\title{
Pelvic and buttock hypoplasia reconstructed with anatomical breast implants
}

\author{
Felicity Page, ${ }^{1}$ Ayad Harb, ${ }^{2}$ Garth Titley ${ }^{2}$
}

${ }^{1}$ Department of Plastic Surgery, University Hospital of North Staffordshire NHS Trust, Stokeon-Trent, UK

${ }^{2}$ Queen Elizabeth Hospital Birmingham, Birmingham, UK

Correspondence to Felicity Page,

felicitypage@doctors.org.uk

Accepted 25 December 2017

\section{SUMMARY}

Radiation therapy is used in the management of a number of childhood cancers and can have significant effects on skeletal growth. We present the case of a 35-year-old woman who developed a hypoplastic pelvis and buttocks following radiotherapy for rhabdomyosarcoma of the vagina at the age of 2. At the age of 25, the patient underwent bilateral buttock augmentation with a two-stage reconstruction using tissue expansion followed by definitive augmentation with anatomical breast implant insertion. The patient continues to have a satisfactory outcome 10 years following reconstruction, having undergone a single uplift procedure and exchange of implants through the original incision 9 years postoperatively. This case represents a unique reconstructive challenge to plastic surgeons and was successfully managed with a novel approach.

\section{BACKGROUND}

Buttock and pelvic hypoplasia are rare, but can occur following childhood radiotherapy. ${ }^{1}$ The hypoplasia becomes increasingly apparent with skeletal maturity. Buttock reconstruction for such unique cases omplete buttock hypoplasia represents a reconstructive challenge. We present a case in which tissue expansion, followed by insertion of anatomical breast implants, was used to give good buttock size and contour.

\section{CASE PRESENTATION}

A 25-year-old woman presented with a hypoplastic pelvis and buttocks following radiotherapy for childhood rhabdomyosarcoma of the vagina. The hypoplasia had become more apparent as

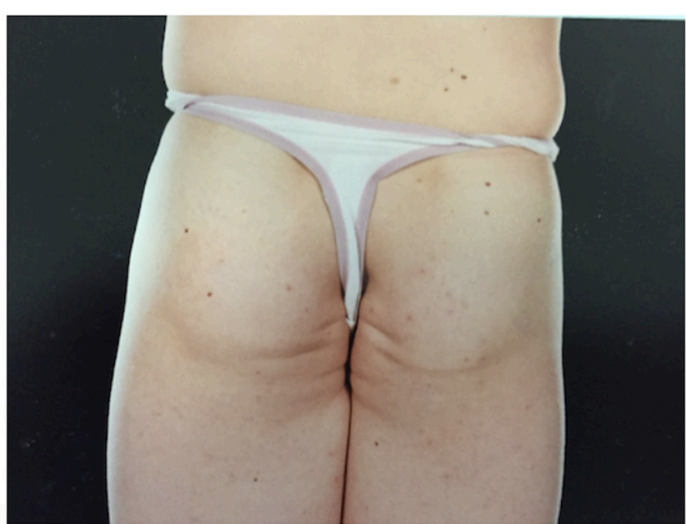

Figure 1 Buttocks preaugmentation.

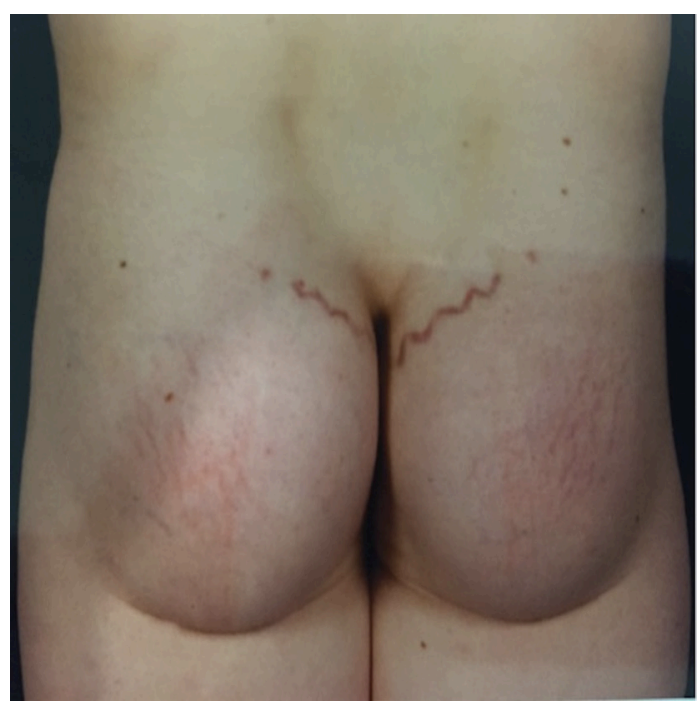

Figure 2 Postoperative result.

she reached skeletal maturity. The patient had concerns over the appearance of her buttocks; she felt they were 'shapeless' and 'small' and she had difficulty finding clothes to fit. Examination revealed hypoplastic buttocks which were flat and lacked contour. There was reasonable underlying buttock musculature with symmetrical hypoplasia. The subcutaneous fat layer was relatively thin but otherwise the soft tissue was of good quality (figure 1).

The off label use of breast implants to achieve buttock augmentation in this unique case was discussed with the patient, in particularly the risk of rupture.

Surgical management involved a two-stage procedure with initial tissue expansion over a period of 5 months. Definitive augmentation was then performed with immediate exchange of expanders for anatomical $280 \mathrm{~mL}$ silicone breast implants inserted in a supramuscular plane (figure 2). This plane was chosen as there was adequate soft tissue coverage available and it was safer. For insertion of the implants, a staggered incision was made at the superior pole of the buttock with the aim of maintaining good buttock contour and avoiding scar stretch inferiorly. Furthermore, a superior incision was chosen to enable subsequent lifting procedures or implant replacement, which in this case were very likely, without the need for further skin incisions. The incision was easily hidden in the patients' underwear. 


\section{OUTCOME AND FOLLOW-UP}

The outcome was satisfactory for 9 years following reconstruction, without evidence of capsular contracture. She recently represented requesting buttock tightening. MRI imaging identified that the implants had ruptured. Subsequent exchange of implants and an uplift procedure through the original incision was carried out, with a satisfactory outcome.

\section{DISCUSSION}

Radiation is used in the management of a number of childhood cancers and can have significant adverse effects on skeletal growth. Rarely, if used on the pelvic organs, it can lead to pelvic and buttock hypoplasia, ${ }^{12}$ with psychosocial consequences for the patient. ${ }^{3}$

This case presented both cosmetic and reconstructive challenges. Buttock augmentation is performed extensively throughout the world for cosmetic purposes. Typical buttock implants are large, flattened silicone-filled implants which are placed in a deep plane and covered with the existing buttock fat. This type of implant was not suitable in this case, as there was a lack of adequate skin and subcutaneous tissue coverage, which would be needed for a traditional buttock augmentation. Furthermore, the desired projection and volume would have necessitated an extremely large buttock implant, well outside the confines of the small boney frame and hypoplastic anatomy in this patient. Fat grafting was not an option in this patient due to her very petite frame with limited options for fat harvesting.

Buttock augmentation is a non-standard indication for the use of breast implants. The silicone shell of a breast prosthesis is considered to be less durable than that of a buttock prosthesis. This suggests that there is an increased risk of rupture due to the mechanical shear and compression forces placed on the buttocks when breast implants are used. In this case, given the atypical dimensions of the patients' pelvis and atrophic buttock fat, it was felt that anatomically shaped breast implants would enable a superior reconstructive outcome. They provided the appropriate volume and projection of the buttock within the anatomical constraints and created a natural looking shape and gluteal crease. The staggered superior incision maintained a natural contour and gave ideal access for subsequent uplift procedures. The patient was also petite.

The patient had a heavy fall onto her buttocks which may have accounted for the implant rupture 9 years postoperatively.

\section{Learning points}

- Pelvic and buttock hypoplasia following childhood radiotherapy may present to the plastic surgery department for reconstruction.

- Such cases are unusual and can be challenging to reconstruct.

- Anatomical breast implants are safe and can be used for cases of buttock augmentation to provide superior outcomes on an individual basis.

- Patients should be counselled about the off-label use of breast implants for buttock augmentation prior to their use.

This case illustrates a novel approach to buttock augmentation in highly unusual circumstances. Anatomical breast implants are safe and their use should be considered on an individual patient basis in gluteal augmentation to provide a superior outcome for individual patients.

Contributors All authors: involved in the development, execution and editing of the work; have seen and agree to the submitted version of the case report, and bear responsibility for it. FP: contributed to the planning, conduct and write up of the case report. $\mathrm{AH}$ : contributed to the planning and design of the article, and the conduct and write up of the article. GT: also contributed to the conception and design, acquisition of the data and write up of the case report.

Disclaimer The material is original and has not been published or submitted for publication elsewhere. If accepted, the case report will not be published elsewhere in the same or similar form, in English or in any other language, without written consent of the copyright holder.

Competing interests None declared.

Patient consent Obtained.

Provenance and peer review Not commissioned; externally peer reviewed.

(C) BMJ Publishing Group Ltd (unless otherwise stated in the text of the article) 2018. All rights reserved. No commercial use is permitted unless otherwise expressly granted.

\section{REFERENCES}

1 Stauss J, Connolly LP, Drubach LA, et al. Pelvic hypoplasia after radiation therapy. Clin Nucl Med 2003;28:847-8.

2 Butler MS, Robertson WW, Rate W, et al. Skeletal sequelae of radiation therapy for malignant childhood tumors. Clin Orthop Relat Res 1990;251:235-40.

3 Goldwein JW. Effects of radiation therapy on skeletal growth in childhood. Clin Orthop Relat Res 1991:262:101-7.

Copyright 2017 BMJ Publishing Group. All rights reserved. For permission to reuse any of this content visit

http://group.bmj.com/group/rights-licensing/permissions.

BMJ Case Report Fellows may re-use this article for personal use and teaching without any further permission.

Become a Fellow of BMJ Case Reports today and you can:

- Submit as many cases as you like

- Enjoy fast sympathetic peer review and rapid publication of accepted articles

- Access all the published articles

Re-use any of the published material for personal use and teaching without further permission

For information on Institutional Fellowships contact consortiasales@bmjgroup.com

Visit casereports.bmj.com for more articles like this and to become a Fellow 